\title{
Green-roof as a solution to solve stormwater management issues? Assessment on a long time period at the parcel scale
}

\author{
P.-A. VERSINI ${ }^{1}$, G. PETRUCCI ${ }^{1,2}$ \& B. DE GOUVELLO ${ }^{1,3}$ \\ 1 LEESU-ENPC, 6-8 avenue Blaise Pascal 77455 Champs sur Marne, France \\ pierre-antoine.versini@leesu.enpc.fr \\ 2 Vrije Universiteit Brussel (VUB), Earth System Sciences (ESSc), Pleinlaan, 2, 1050 Brussels, Belgium \\ 3 CSTB, 84 avenue Jean Jaurès 77447 Champs-sur-Marne, France
}

\begin{abstract}
Experimental green-roof rainfall-runoff observations have shown a positive impact on stormwater management at the building scale; with a decrease in the peak discharge and a decrease in runoff volume. This efficiency of green-roofs varies from one rainfall event to another depending on precipitation characteristics and substrate antecedent conditions. Due to this variability, currently, green-roofs are rarely officially used as a regulation tool to manage stormwater. Indeed, regulation rules governing the connection to the stormwater network are usually based on absolute threshold values that always have to be respected: maximum areal flowrate or minimum retention volume for example. In this context, the aim of this study is to illustrate how a green-roof could represent an alternative to solve stormwater management issues, if the regulation rules were further based on statistics. For this purpose, a modelling scheme has been established at the parcel scale to simulate the hydrological response of several roof configurations: impervious, strictly regulated (in terms of areal flow-rate or retention volume), and covered by different types of green-roof matter. Simulations were carried out on a long precipitation time period (23 years) that included a large and heterogeneous set of hydrometeorological conditions. Results obtained for the different roof configurations were compared. Based on the return period of the rainfall event, the probability to respect some regulation rules (defined from real situations) was assessed. They illustrate that green-roofs reduce stormwater runoff compared to an impervious roof surface and can guarantee the respect of the regulation rules in most of the cases. Moreover, their implementation can appear more realistic than that of other infrastructures strictly complying with regulations and demanding significant storage capacity.
\end{abstract}

Key words green-roof; storm water source control; hydrological modelling; SWMM

\section{INTRODUCTION}

Green-roofs have become relatively common over the last 20 years in urban areas. The annual greenroof covering is estimated to reach $2 \mathrm{~km}^{2}$ in France and even more than $10 \mathrm{~km}^{2}$ in Germany (Lassalle 2012). This success is due to two main reasons. First, roof areas represent a significant part of the surfaces of city centres where no space is available for new infrastructures (about $40-50 \%$ of the impervious areas, cf. Dunnett and Kingsbury 2004). Secondly, green-roofs provide and contribute several benefits: e.g. reducing the heat island by increasing evapotranspiration (Takebayashi and Moriyama 2007, Santamouris 2012), improving the quality of the air (Banting et al. 2005), protecting biodiversity, and managing urban runoff.

Indeed, urban runoff management is surely the most significant argument used to promote the implementation of green-roofs. At the building scale, green-roofs appear to efficiently control the quantity of urban runoff. These positive quantitative impacts have already been studied through several works based on observation or modelling. Typically, experimental green-roofs were instrumented to collect continuous runoff and precipitation data on short periods of time (not exceeding 3 years): see Monterusso et al. (2004), Bengtsson et al. (2005), Dunnett et al. (2008), Palla et al. (2008b), Voyde et al. (2010), Gregoire and Clausen (2011), Stovin et al. (2012), Fassman-Beck et al. (2013) among others. From this point of view, green-roofs can be considered as parcel-scale facilities, also known as stormwater Source Control Measures, as well as porous pavements, harvesting tanks, soakaways or ponds. Coping with urbanization and its related problem of space, this kind of infrastructure is able to manage stormwater at a small scale and has gained relevance over traditional sewer approaches (Petrucci et al. 2013). Often, these infrastructures have to fulfil regulation rules established by local stormwater managers in order to connect the parcel to the sewer network.

For now, green-roofs are not directly used to ensure compliance with regulation rules. Indeed, green-roof impacts can be variable in time, depending on the initial saturation of the substrate and rainfall event characteristics. In these conditions, it appears quite difficult to always guarantee the 
respect of such rules, whether expressed in terms of flow-rate or volume. The aim of this paper is to study how green-roofs can be used in stormwater management and how their performance may be expressed to be taken into account in stormwater management policies. To achieve this goal, a modelling framework has been proposed to assess the hydrological impact of a green-roof on a virtual parcel, using a long-term rainfall dataset. Their impacts and ability to ensure regulation rules shall be detailed in a statistical manner.

\section{METHODOLOGY}

\section{Hydrological modelling}

The Storm Water Management Model (SWMM 5.0, see Rossman 2004) was used in this study. It is a dynamic rainfall-runoff model, especially developed by the United States Environmental Protection Agency (EPA) for urban/suburban areas. The model of the sewer network (including junction nodes, conduits, and specific infrastructures like weirs, orifices or storage units), is designed to simulate and estimate the hydrological behaviour of a typical basin. In this work, the SWMM module called "Bio-retention Cell" was significantly modified to simulate the hydrological response of green-roofs. This new module was inspired by the model developed by Berthier et al. (2011) that represented each layer of a green-roof infrastructure (vegetation, growing medium and drainage) by three different reservoirs. The model parameters were adjusted for two configurations comprising an extensive vegetation (sedum), a growing medium layer and a drainage layer with expanded polystyrene The two configurations corresponding to experimental green-roof set-ups were implemented on the site of Trappes ( $25 \mathrm{~km}$ southwest from Paris, France), differing by the depth of the growing medium. For the first one, SE3Y, the thickness was $3 \mathrm{~cm}$ and for the second one, SE15Y, the thickness was $15 \mathrm{~cm}$. Satisfactory model fitting was obtained for both configurations, especially for the largest rainfall events. Dynamics of runoff were well reproduced with NashSutcliffe efficiencies (Nash and Sutcliffe, 1970) close to 0.8 at the storm event scale. Moreover, the water balance was accounted for with an approximate $10 \%$ error in runoff volumes. More details on model description, calibration and validation, are available in Versini et al. (2014).

\section{Theoretical case study}

A virtual parcel was designed, inspired by the denser urbanization areas of the Paris region, in particular of the Seine-Saint-Denis county, where parcels can be completely impervious. It includes buildings characterized by a roof area of approximately $100 \mathrm{~m}^{2}$ and a supplementary impervious area of $100 \mathrm{~m}^{2}$ (including roads and parking). Both surfaces are connected at the same outlet. Topographically, the parcel is quite flat and characterized by a low slope $(0.3 \%)$.

Based on the analysis of source control policies by Petrucci et al. (2013) on several French case studies, several regulation rules were tested. They correspond to the traditional rules that can be implemented in the region of Paris:

- Flow-rate limitations: the discharge at the parcel outlet has to be lower than a reference threshold. Two different thresholds are applied here: 2 and $10 \mathrm{~L} / \mathrm{s} / \mathrm{ha}$.

- Volume limitations: the parcel has to be able to collect and store a certain volume of rainwater. Two volume scenarios are applied here: 5 and $10 \mathrm{~mm}$.

The compliance of green-roofs with these rules is tested by considering the whole roof area of the parcel covered by each of the two green-roof configurations modelled (SE3Y and SE15Y). For comparison, some other systems of stormwater source control implemented on the roofs that were tested for each rule:

- Flow-rate limitations were modelled by installing a reservoir covering the whole roof surface (and characterized by a height of $15 \mathrm{~cm}$ ). The reservoir outfall was modelled by a stagedischarge curve. The parameters of the curve were adjusted to respect the flow-rate limitation following recommendations made by Petrucci et al. (2013).

- Volume limitations are modelled by installing a depression storage covering the whole roof surface and whose height was equal to the prescribed infiltration depth (5 and $10 \mathrm{~mm})$. The remaining water was routed to the outlet without any regulation. 
These roof infrastructures were designed to ensure that the flow-rate and volume regulation of the entire parcel was accounted for, thus considering an impervious area double of the roof area.

In summary, seven simulations were performed: one for the current situation with an impervious roof (imp), two with a flow-rate limitation (RegulV5 and regulV10), two with a volume limitation (Regulq2 and Regulq10) and two with a green-roof implementation (SE3Y and SE15Y). Additional simulations were performed at the roof outlet without considering the remaining impervious area.

\section{Hydrological data}

A continuous precipitation dataset was provided by the Water Direction of the Seine-Saint-Denis county; ranging from 1990 to 2012 with a time resolution of 5 minutes. For this period, the mean annual rainfall was $664 \mathrm{~mm}$ (snow was not considered), with a minimum of $472 \mathrm{~mm}$ in 2002 and a maximum of $891 \mathrm{~mm}$ in 2000. Monthly average evapotranspiration data produced by Meteo France was used to represent evaporation.

By using this precipitation data as input of the hydrological modelling, 6632 hydrological events were extracted. Here, a hydrological event is defined as the period between the first rainfall and the end of the hydrograph (all the simulated runoff has flowed out of the system). Only rainfall events for which duration was lower than 1 day were conserved. These events differ by their maximal intensity (from 0.2 to $65 \mathrm{~mm} / \mathrm{h}$ ), duration (from 10 minutes to 24 hours) and total rainfall accumulation (from 0.1 to $61 \mathrm{~mm}$ ). For each event, rainfall frequency (i.e. return period) has been determined by comparison with the Intensity-Duration-Curve computed for the Montsouris weather station located at $10 \mathrm{~km}$ from Seine-Saint-Denis County. The repartition of rainfall events is indicated in Table 1.

\section{SIMULATIONS AT THE PARCEL SCALE}

\section{General results}

Comparing to the current and impervious situation, the different types of infrastructure induce a runoff volume reduction. Mean annual retention was 19\% for the SE3Y green-roof configuration and 32\% for the SE15Y one. The same order of magnitude was obtained with volume regulation infrastructures: $22 \%$ for RegulV5 and $27 \%$ for RegulV10. The retention was lower for both flow-rate regulation infrastructures (6\% for Regulq2 and Regulq10) where evapotranspiration was not a key factor.

Flow-frequency curves are illustrated in Fig. 1. They represent the distribution of discharge on the whole studied period for the seven simulations and allow for the analysis of the flow regimes for

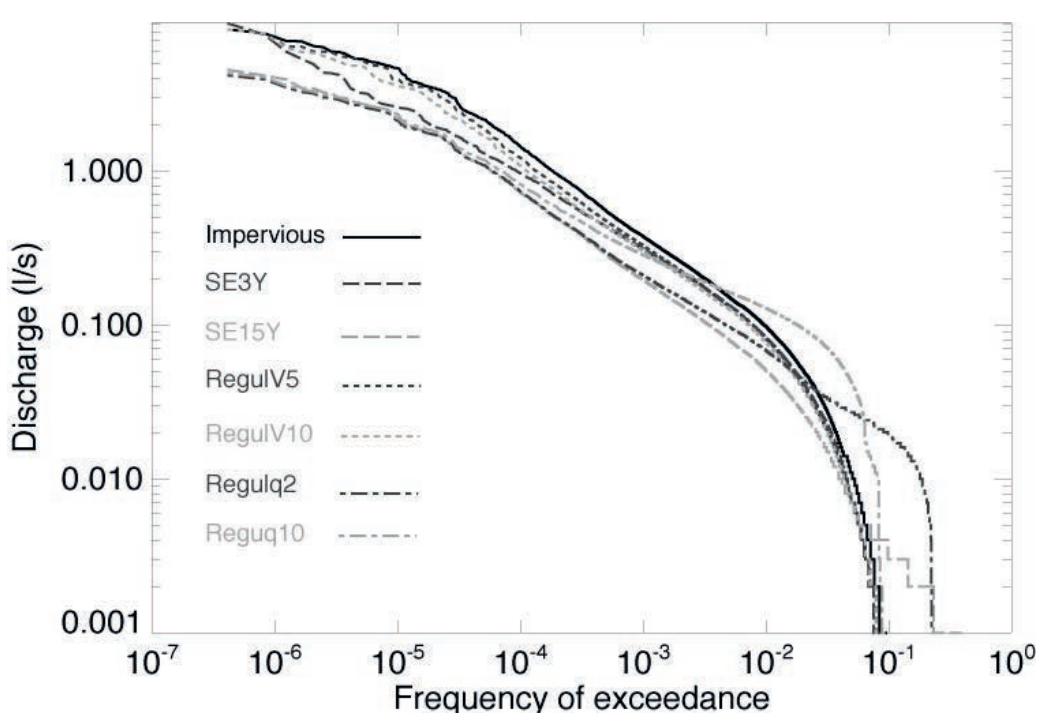

Fig. 1 Flow-frequency curves: comparison of discharge distribution for the impervious case, green-roof configurations (SE3Y and SE15Y), volume regulations (RegulV5 and RegulV10) and both discharge regulations (Regulq2 and Regulq10). 
Table 1 Ratio (expressed in \%) of rainfall events for which the regulation rule is respected depending on the infrastructure implementation and the return period of the rainfall event.

\begin{tabular}{|c|c|c|c|c|c|c|c|c|c|}
\hline & \multicolumn{8}{|c|}{ Return period of the rainfall events } \\
\hline & & $<1 \mathrm{~m}$ & $1 \mathrm{~m}<<3 \mathrm{~m}$ & $3 \mathrm{~m}<<6 \mathrm{~m}$ & $6 \mathrm{~m}<<1 \mathrm{y}$ & $1 \mathrm{y}<<2 \mathrm{y}$ & $2 \mathrm{y}<<5 \mathrm{y}$ & $5 y<<10 y$ & $>10 \mathrm{y}$ \\
\hline & \# events & 5820 & 333 & 77 & 59 & 21 & 13 & 6 & 3 \\
\hline $\mathrm{V}$ & $\operatorname{Imp}$ & 0.0 & 0.0 & 0.0 & 0.0 & 0.0 & 0.0 & 0.0 & 0.0 \\
\hline \multirow[t]{3}{*}{$=5 \mathrm{~mm}$} & SE3Y & 99.8 & 54.6 & 14.3 & 13.6 & 19.0 & 61.5 & 50.0 & 0.0 \\
\hline & SE15Y & 99.8 & 57.7 & 83.1 & 94.9 & 100 & 100 & 100 & 100 \\
\hline & RegulV5 & 99.8 & 54.6 & 18.3 & 22.0 & 19.0 & 38.5 & 33.0 & 33.0 \\
\hline V & $\operatorname{Imp}$ & 0.0 & 0.0 & 0.0 & 0.0 & 0.0 & 0.0 & 0.0 & 0.0 \\
\hline$=$ & SE3Y & 92.6 & 10.8 & 2.6 & 8.5 & 0.0 & 0.0 & 0.0 & 0.0 \\
\hline \multirow[t]{2}{*}{$10 \mathrm{~mm}$} & SE15Y & 92.9 & 54.6 & 37.2 & 47.5 & 61.9 & 84.6 & 83.3 & 100 \\
\hline & RegulV10 & 92.7 & 23.7 & 14.7 & 45.8 & 42.9 & 46.1 & 33.3 & 33.3 \\
\hline Q & Imp & 46.5 & 0.3 & 0.0 & 0.0 & 0.0 & 0.0 & 0.0 & 0.0 \\
\hline$=$ & SE3Y & 59.7 & 0.3 & 0.0 & 0.0 & 0.0 & 0.0 & 0.0 & 0.0 \\
\hline \multirow[t]{2}{*}{$2 \mathrm{~L} / \mathrm{s} / \mathrm{ha}$} & SE15Y & 62.7 & 0.3 & 0.0 & 0.0 & 0.0 & 0.0 & 0.0 & 0.0 \\
\hline & Regulq2 & 55.3 & 0.3 & 0.0 & 0.0 & 0.0 & 0.0 & 0.0 & 0.0 \\
\hline $\mathrm{Q}$ & Imp & 85.0 & 4.2 & 1.3 & 0.0 & 0.0 & 0.0 & 0.0 & 0.0 \\
\hline$=$ & SE3Y & 92.9 & 11.4 & 3.9 & 1.7 & 0.0 & 0.0 & 0.0 & 0.0 \\
\hline \multirow[t]{2}{*}{$10 \mathrm{~L} / \mathrm{s} / \mathrm{ha}$} & SE15Y & 94.9 & 30.3 & 24.7 & 8.5 & 0.0 & 0.0 & 0.0 & 0.0 \\
\hline & Regulq10 & 90.8 & 9.0 & 5.2 & 1.7 & 0.0 & 0.0 & 0.0 & 0.0 \\
\hline
\end{tabular}

both extreme events and low flows. Both green-roof configurations decreased the frequency of intermediate discharge (between 5 and $0.01 \mathrm{~L} / \mathrm{s}$ ), while SE3Y green-roof was less effective than $\mathrm{SE} 15 \mathrm{Y}$ on highest discharge (greater than $5 \mathrm{~L} / \mathrm{s}$ ). It has to be noted that volume regulation infrastructures have very little influence on the discharge distribution: resulting flow-frequency curves are similar to that of the current situation. Finally, as expected, flow-rate regulation infrastructures influence the distribution of the peak values (the greatest flow-rate is $4 \mathrm{~L} / \mathrm{s}$ versus $10 \mathrm{~L} / \mathrm{s}$ for the current situation). Nevertheless, as already mentioned in Petrucci et al. (2013), a reduction in low frequency flow-rates corresponds to an increase of flow-rates for higher frequencies.

\section{Respect of volume limitations}

In contrast with impervious areas, green-roofs are able to retain the prescribed rain volume (5 or 10 $\mathrm{mm}$ ) in a large number of cases (approximately $90 \%$ of all the events). Model performance was clearly better for the thicker substrate, which was able to ensure volume regulation compliance for the whole set of return periods (approximately $80 \%$ for each return period category). For a limitation of $10 \mathrm{~mm}, \mathrm{SE} 3 \mathrm{Y}$ green-roof is effective only for rainfall events characterized by a return period lower than 1 month (representing, however, more than $90 \%$ of the events). Indeed, this $10 \mathrm{~mm}$ regulation is hard to satisfy because the $3 \mathrm{~cm}$ substrate is not able to retain the required volume for both surfaces (roof and impervious). Moreover, it could not have the time to recover its retention capacity between two events. This recovery time problem emerges also for the volume regulation infrastructure, which appears less effective than SE15Y green-roof having a higher retention capacity. Its storage capacity should be extended to reach a similar performance.

Note that when only the roof area is considered (and not the remaining impervious area), greenroofs satisfy the volume regulations for almost every event and for every return period.

\section{Respect of flow-rate limitations}

The impact of flow-rate regulation is not substantial due to the discharge produced by the additional impervious area, which is not regulated. The corresponding flow component can easily reach some values higher than the prescribed flow rate. Green-roofs, as flow-rate infrastructures, reduce the occurrence of high flows only for the smallest events: return period lower than one month for the most restrictive rule $(2 \mathrm{~L} / \mathrm{s} / \mathrm{ha})$ and lower than 6 months for the less restrictive $(10 \mathrm{~L} / \mathrm{s} / \mathrm{ha})$. Only the 
consequence of common events (return period lower than 1 month) are avoided: $60 \%$ of the cases for the $2 \mathrm{~L} / \mathrm{s} /$ ha regulation and around $90 \%$ for the $10 \mathrm{~L} / \mathrm{s} /$ ha regulation.

By considering only the roof component, green-roofs appear to be very efficient. SE3Y ensures high flow-rate reduction $(\mathrm{q}=10 \mathrm{~L} / \mathrm{s} / \mathrm{ha})$ in more than half of events characterized by a return period lower than 6 months, whereas SE15Y performs satisfactorily for $80 \%$ of the events and for every return period. Results are less substantial for low flow-rate reduction $(\mathrm{q}=2 \mathrm{~L} / \mathrm{s} / \mathrm{ha}): 75 \%$ of the events ( $\mathrm{T}<3$ months) for SE3Y and $80 \%$ of the events on the whole frequency set for SE15Y.

\section{DISCUSSIONS AND CONCLUSIONS}

A simulation framework has been developed to assess the hydrological impact of green-roofs and their ability to ensure compliance with regulation rules related to sewer network connection at the parcel scale. It includes a specific module to simulate green-roof hydrological impacts and compares its response to other regulation infrastructures. Following application on a long-term rainfall dataset (23 years), green-roofs appear to be efficient tools that can be promoted in stormwater policies.

Their performance is particularly relevant in volume regulation as substrate retention capacity is able to store a significant part of the rainfall. Achieving similar results with volume regulation infrastructures would cause an oversizing of the storage capacity. Nevertheless, green-roofs appear limited in flow-rate regulation at the parcel scale because the complementary impervious area is responsible for high discharge. Only the consequences of common events (return period lower than 1 month) are avoided. By only considering the roof area, green-roof - especially the thicker one are we able to ensure volume reduction for more events, and flow-rate reduction for $75 \%$ of the events, of all return periods.

It has to be noted that the hydrological model representing green-roof behaviour has been calibrated on a short time period (18 months) during which no severe event was observed (the maximum exceeded return period was equal to 1 year). Thus, the model was implicitly developed to reproduce common events, and its reliability for rare events characterized by more intense precipitation can only be supposed (note that, in these cases, the substrate is often saturated and a green-roof acts as an impervious area). Moreover, more realistic evapotranspiration data are certainly required to better estimate the green-roof behaviour between two rainfall events.

Nevertheless, the presented results illustrate the interest of using green-roofs in stormwater management. If the regulation rules were more flexible, such infrastructure would solve operational issues in many cases. Combined with other stormwater source controls or/and retention infrastructures, in particular for the control of roads and parking runoff, green-roofs could be efficient tools to ensure regulation rules at the parcel scale. Moreover, it should be noted that stormwater source control is just one of the benefits provided by green-roofs.

Acknowledgements This work has been supported by the French C2D2 framework programme through the TVGEP project and the Blue Green Dream European project. The authors would also like to thank the Water Direction of the Seine-Saint-Denis county for providing hydrometeorological data.

\section{REFERENCES}

Banting, D., et al. (2005) Report on the Benefits and Costs of Green-roof Technology for the City of Toronto.

Bengtsson, L., Grahn, L. and Olsson, J. (2005) Hydrological function of a thin extensive green-roof in southern Sweden. Nordic Hydrology 36, 259-268.

Berthier, E., Ramier, D. and de Gouvello, B. (2011) Simulation of green-roof hydrological behavior with a reservoir model. In: International Water Association (Editor), 12th International Conference on Urban Drainage, Porto Alegre (Brazil), pp. 8.

Dunnett, N. and Kingsbury, N. (2004) Planting Green-roofs and Living Walls Timber Press, Portland, 336 pp.

Dunnett, N., et al. (2008) Influence of vegetation composition on runoff in two simulated green-roof experiments. Urban Ecosystems 11(4), 385-398.

Fassman-Beck, et al. (2013) 4 Living roofs in 3 locations: does configuration affect runoff mitigation? Journal of Hydrology 490, 11-20.

Gregoire, B. G. and Clausen, J. C. (2011) Effect of a modular extensive green-roof on stormwater runoff and water quality. Ecological Engineering 37(6), 963-969.

Hilten, R. N., Lawrence, T. M. and Tollner, E. W. (2008) Modeling stormwater runoff from green-roofs with HYDRUS-1D. 
Journal of Hydrology 358(3-4), 288-293.

Lassalle, F. (2012) Panorama technique, historique et géographique, Paris (France). 20th November 2012

Monterusso, M. A., et al. (2004) Runoff water quantity and quality from green-roof systems. Acta Horticulturae (ISHS) 639, 369-376.

Nash, J. E. and Sutcliffe, J. V. (1970) River flow forecasting through conceptual models part I - a discussion of principles. Journal of Hydrology 10(3), 282-290.

Nature, E. (2003) Green-roofs: Their Existing Status and Potential for Conserving Biodiversity in Urban Areas, Peterborough.

Palla, A., Lanza, L. G. and La Barbera, P. (2008) A green-roof experimental site in the Mediterranean climate. In: 11th International Conference on Urban Drainage, Edinburgh (Scotland).

Petrucci, G., et al. (2013) Do stormwater source control policies deliver the right hydrologic outcomes? Journal of Hydrology $485,188-200$.

Rossman, L. A. (2004) Storm water management model User's manual version 5.0, Water Supply and Water Resources Division, National Risk Management Research Laboratory, Cincinnati (USA).

Santamouris, M. (2012) Cooling the cities - a review of reflective and green-roof mitigation technologies to fight heat island and improve comfort in urban environments. Solar Energy (in press).

Stovin, V., Vesuviano, G. and Kasmin, H. (2012) The hydrological performance of a green-roof test bed under UK climatic conditions. Journal of Hydrology 414-415, 148-161.

Takebayashi, H. and Moriyama, M. (2007) Surface heat budget on green-roof and high reflection roof for mitigation of urban heat island. Building and Environment 42(8), 2971-2979.

Versini, P.-A., et al. (2014) Assessment of the hydrological impacts of green-roof : from building scale to basin scale. Journal of Hydrology (submitted).

Voyde, E., Fassman, E. and Simcock, R. (2010) Hydrology of an extensive living roof under sub-tropical climate conditions in Auckland, New Zealand. Journal of Hydrology 394(3-4), 384-395. 
